Patient safety

\section{The National Patient Safety Agency}

\section{T Stephenson}

\section{Assisting the NHS to identify and learn when things go wrong}

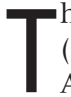
e National Patient Safety Agency (NPSA) is a Special Health Authority formed in 2001 to improve patient safety in the NHS across England and Wales. Currently, it has a budget of just over $£ 15$ million. The NPSA was created following the publication of two key reports by the Chief Medical Officer, Professor Sir Liam Donaldson, An organisation with a memory and Building a safer NHS. ${ }^{2}$ An organisation with a memory refers to the death of Wayne Jowett following an inadvertent intrathecal vincristine injection, the 23rd such incident reported worldwide (and the 14th in 15 years in the United Kingdom). ${ }^{3}$

A central tenet of the NPSA's creation was that it should assist all those involved in healthcare to identify and learn when things go wrong. When patient safety incidents occurred in the past they may not have been reported locally because they were not seen as important, staff were too busy, patient harm was averted (often known as a prevented patient safety incident or "near miss"), or because of a fear of a blame and punish culture. We need to move from automatically blaming individual front-line staff $^{3}$ to an understanding of the underlying factors in the system which are more often responsible for incidents. ${ }^{4}$ For too long, the system has blamed the individual and exhorted staff "to try harder" or "be more careful". The vast majority of NHS staff work very hard and are very careful, but human error cannot be eradicated by such simplistic calls to arms. In other cases, lessons were learned locally but not disseminated nationally. To overcome this, all clinicians and NHS organisations need to have the safety of patients at the heart of their practice. Safety is not an "add on", but an integral feature of healthcare systems and processes.

A contrast has been drawn with the aviation industry. In healthcare, errors may not be reported because of fears of disciplinary action. Aircrew face disciplinary action if it transpires that they have not reported a safety incident. It has been estimated that there are 900000 adverse events per year in the NHS, ${ }^{1}$ perhaps half in acute hospitals, leading to an additional three million bed days. The total cost to the NHS of these adverse events in extra bed days alone would be around $£$ l billion a year. $^{5}$

If we just consider errors arising from prescribing, UK prescribers (mostly doctors) generate 1.5 million GP and 0.5 million hospital prescriptions per day. A single universal solution may not be feasible therefore. This is where comparisons with aviation break down. There are not two million aircraft flights per day in the UK. There may be two million in-flight decisions taken per day, but not by 100000 different pilots on 100000 "inpatient flights" and 0.5 million "outpatient flights". Therefore, the scale of the problem is much bigger than in aviation, although the human cost of a single error is usually much less.

\section{THE NATIONAL REPORTING AND LEARNING SYSTEM}

In order to improve patient safety, it is necessary to know the scale and type of problems, so that the NPSA can prioritise its work accordingly. It is also helpful to know if patient safety issues cluster within one region, specialty area, or care setting since this may give clues to the root of the problem. One of the statutory functions of the NPSA is to devise, implement, and monitor a national reporting system for patient safety incidents. Ensuring NHS-wide implementation of the National Reporting and Learning System (NRLS) remains the NPSA's highest priority. It has been decided that the system should be anonymous, to encourage reporting and respect the confidentiality of those who take the time to report to the Agency, although this limits the ability of the NPSA to seek clarification or updates.

Healthcare staff will be able to report incidents to the NRLS through their organisation's existing reporting system. The NPSA is aware that not all staff feel comfortable reporting incidents to their local organisations, and in response to these anxieties, the NPSA has developed the eForm, an intuitive electronic reporting form that takes less than 10 minutes to complete. The eForm will allow staff to report independently, confidentially, and anonymously, and is now available on the NPSA's website, although the Agency encourages staff to share these reports so that local learning and action can take place. The NPSA is also exploring ways to allow patients, their carers, and the public to report problems affecting patient safety.

There may be difficulties analysing what will potentially be a large body of unverifiable reports, but the first aim is to look for clusters and trends which can inform the future research and work of the NPSA.

The NPSA is in the process of rolling out the NRLS across all NHS organisations in England and Wales to enable all staff to report on patient safety incidents, including "near misses" which cause no actual harm. Experience from the aviation industry shows that as reporting rises, the number of serious events begins to decline. Paradoxically, an increase in reporting of patient safety incidents will be a sign that the NPSA has been successful in encouraging an open and fair culture in which we can all learn from the mistakes of others, truly an Organisation with a Memory.

\section{EXAMPLES OF SYSTEMS SAFETY SOLUTIONS}

However, some patient safety issues are already obvious. The NPSA has tackled some of these pending the implementation of the NRLS. Two examples illustrate how longstanding systems problems created error prone situations which led to recurrent patient safety incidents.

Safety of infusion pumps was highlighted by incidents when batteries went flat during patient transfer and when patients were unintentionally administered excessive and life threatening bolus doses of drugs. A pilot study involving six acute Trusts by the NPSA revealed that, on average, each Trust owned 1095 infusion pumps at a total cost of $£ 1.6$ million, each Trust had 31 different types of pump, and 65\% were not utilised at any one time. Annual maintenance costs for each pump varied from $£ 20$ to $£ 200$. For England and Wales, this represents approximately 200000 pumps costing $£ 300$ million. This situation arose because each directorate purchased its own devices, instead of a Trust wide policy, and therefore purchased the number to meet a "worst case" scenario for that directorate, irrespective of unused stocks elsewhere in the hospital. A $10 \%$ reduction in the stockpile would save the NHS £33 million in new purchases (when the current devices expire) and $£ 400000-£ 4$ million per 


\section{Practice points}

- Safety is not an "add on"

- In the NHS each year, including adult and paediatric patients, there are 624 million prescriptions, 300 million GP visits, 13 million OPD visits, 5.3 million admissions, 2.9 million "999" calls, and an estimated 900000 adverse events per year in the NHS

- We need an open and fair culture in which staff can report errors

- Human error cannot be totally eradicated

- Therefore, systems must be mistake proofed against individual human error, wherever feasible

annum recurrently in maintenance costs saved.

Two new infusion devices initiatives will improve safety for patients. Firstly, a one-stop information website has been established at www.pasa.nhs.uk/ infusiondevices which helps staff to purchase, manage, and use infusion devices safely and efficiently. Secondly, Trusts are encouraged to establish "equipment libraries" with the minimum number of different devices compatible with the Trust's services. What we can learn from this example is that this approach promotes centralisation (avoiding wasteful under-utilisation), standardisation (easier staff training), and ensures devices are properly stored, labelled, cleaned, maintained, and charged. These benefits are likely to accrue if the same strategy is adopted in relation to other expensive and complex equipment.

Deaths have occurred when potassium chloride has been injected intravenously instead of sodium chloride. Any design engineer, looking at ampoules of the two solutions, would stare in disbelief. Two colourless liquids with no odour, both in identically sized clear glass ampoules with tiny black typescript. The crucial difference lies between " $\mathrm{K}$ " and "Na". A subtle distinction in an emergency situation.

In July 2002, the NPSA issued its first patient safety alert. It advised on preventing further accidental overdoses with intravenous potassium chloride concentrate that have been misidentified with sodium chloride $0.9 \%$ and water for injections. The alert identified safe medication practice recommendations concerning the prescribing, distribution, storage, and preparation of potassium chloride solutions in hospitals. They recommended the withdrawal of concentrated potassium solutions from ward stock and replacement of them with ready to use infusion products. Before publication, formal written safety controls for potassium chloride concentrate were only present in $25 \%$ of the trusts taking part in the initiative. After publication, $68 \%$ of these trusts had implemented all the recommended safe medication practices, and this number is expected to continue to rise. There have been significant reductions in the number of general ward areas and other clinical areas outside of intensive care and high dependency areas holding stocks of potassium chloride concentrate. ${ }^{6}$ In this example, the authority of a national patient safety alert empowered local pharmacists to act to withdraw concentrated $\mathrm{KCl}$ ampoules from ward areas. Prior to the alert, medical and nursing staff may have felt that pharmacists were intruding on their "clinical freedom" to administer whatever electrolyte solutions they thought appropriate.

\section{SAFETY PRIORITIES FOR CHILDREN}

Some of the NPSA's safety solutions are generic and apply to all age groups, for

Children's medication errors (includes prescribing, dispensing, and administering)

- Medication errors are the single largest group of errors by doctors ${ }^{8}$

- Drug errors account for $25 \%$ of medical negligence claims against $\mathrm{GPs}^{9}$

- $6 \%$ of medication prescriptions may include an error; three studies suggest that $2.3-7.5 \%$ of paediatric patients may suffer an adverse drug event as a result ${ }^{10-12}$

- It is estimated that there is one medication error for every 660 admissions to a UK children's hospital ${ }^{13}$

- An estimate of 1675 avoidable medication errors occur per year in paediatric inpatients in England, of which 85 are moderate/severe reactions $^{14}$

- Children vary in weight from $300 \mathrm{~g}$ to over $90 \mathrm{~kg}$ (300-fold range; compared to adults, $40 \mathrm{~kg}$ to $120 \mathrm{~kg}$, a 3 -fold range), and there have been several highly publicised deaths from 10-fold errors in drug doses following miscalculations ${ }^{15} 16$

- Risk factors for medication errors in a paediatric emergency department include: patients seen between 4 am and 8 am, patients with severe disease, medication ordered by a trainee (especially at the beginning a training year), and patients seen during weekends ${ }^{17}$

- Computerised prescribing with computerised decision support decreased serious medication errors by $55 \%{ }^{18}$ 


\section{Case scenario: now and in the future}

Imagine a distressed ventilated newborn weighing $1 \mathrm{~kg}$ is prescribed morphine as sedation. This seems appropriate, although the drug is not licensed for this purpose. The infant is prescribed 15 micrograms $/ \mathrm{kg}$. However, the barely legible and inappropriate abbreviation " $\mathrm{mcg}$ " is interpreted by both of the nurses involved in the administration of the drug as " $\mathrm{mg}^{\prime}$ (milligrams). Unfortunately, the infant can easily be given 15 milligrams because no "tailor-made" paediatric formulation exists for this unlicensed drug and therefore commercially available $2 \mathrm{ml}$ adult vials are stocked on the neonatal intensive care unit containing $10 \mathrm{mg} / \mathrm{ml}$. The infant has a respiratory arrest and, although resuscitated, suffers permanent neurological damage leading to lifelong learning difficulties, cerebral palsy, and incontinence. The litigation costs the NHS over $£ 3$ million.

Staff in the future can anticipate computerised order entry. Even if the doctor inadvertently prescribes 15 milligrams, the software will absolutely bar this prescription being printed out for use in a $1 \mathrm{~kg}$ neonate. Imagine that, coincidentally, the doctor also mistakenly entered the child's weight as $100 \mathrm{~kg}$ la weight for which 15 milligrams would be an appropriate dose for intramuscular or subcutaneous injection). The software will alert the prescriber that, given the patient was only born three days ago (from the date of birth entered at the same time), $100 \mathrm{~kg}$ is an implausible weight. Alternatively, for less extreme examples, the electronic prescriber would be linked by the infant's identity bracelet barcode to the baby's own electronic record (the old fashioned and often illegible "notes") which would contain the most recent weight measurement. An appropriate dose for the child's age and weight will be suggested on-screen, and once the prescription is consistent with this, it will be printed out with MICROGRAMS in capitals accompanied by the reminder NOTE: THIS DOSE IS IN MICROGRAMS, NOT MILLIGRAMS. The computer will never resort to the abbreviation "mcg".

and the number will reduce to 20 with projected savings of $£ 0.5$ billion and a $25 \%$ reduction in staff. As part of this reorganisation, and in recognition of the NPSA's lead role in safety and protection of patients, the NPSA will take on the role of the National Clinical Assessment Authority (NCAA); hospital food, cleanliness, and safe hospital design from NHS Estates; the three National Confidential Enquiries (the National Confidential Inquiry into Suicide and Homicide (NCISH), the Confidential Enquiry into Maternal and Child Health (CEMACH), and the National Confidential Enquiry into Patient Outcome and Death (NCEPOD)); and the Central Office of Research Ethics Committees (COREC).

\section{SUMMARY}

Of the top 20 risk factors which account for nearly three quarters of all deaths annually, adverse in-hospital healthcare events come eleventh. This is above air pollution, alcohol, drugs, violence, and road traffic accidents, and approaching one third of the deaths due to tobacco. ${ }^{19}$ The NPSA was established to be the driving force to improve patient safety. The NRLS is the most ambitious national confidential reporting system in the world. This will inform future research and the development of systems solutions rather than a knee-jerk reaction of individual blame. An important lesson from other industries is that an open and fair culture where safety problems are acknowledged is more important than attributing blame or issuing punishments and sanctions. The NHS spends millions annually on litigation and yet few of these cases lead to national changes in practice. The NPSA aims to change that.

Arch Dis Child 2005;90:226-228.

doi: 10.1136/adc.2004.065896

Correspondence to: Prof. T Stephenson, Professor of Child Health, Queen's Medical Centre, Nottingham NG7 2UH, UK and Clinical
Specialty Advisor to the NPSA, 4-8 Maple St, London WIT 5HD, UK; terence.stephenson@ nottingham.ac.uk

Competing interests: The author is Clinical Specialty Advisor in paediatrics to the National Patient Safety Agency

\section{REFERENCES}

1 Department of Health. An organisation with a memory. London: The Stationary Office, 2000. Available at www.doh.gov.uk/ org.memreport/index.htm.

2 Chief Pharmaceutical Officer, Department of Health. Building a safer NHS for patientsreducing the risk of medication errors. London: Department of Health, 2002

3 Holbrook J. The criminalisation of medical mistakes. BMJ 2003;327:1118-19.

4 Reason J. Human error: models and management. BMJ 2000;320:768-70.

5 Vincent C, Neale G, Woloshynowych M. Adverse events in British hospitals: preliminary retrospective record review. $B M$ 2001;322:517-19.

6 National Patient Safety Agency. Update on the implementation of recommended safety controls for potassium chloride in the NHS. Issued 6 November 2003

7 www.npsa.nhs.uk/advice Towards the safer use of oral methotrexate.

8 Parker S. Nurse prescribers-good for patients? Journal of the Medical Defence Union 1999; 15(3):21-2.

9 Leape LL, Brennan TA, Laird NM et al. The nature of adverse events in hospitalized patients: Results from the Harvard Medical Practice Study II. N Engl J Med 1991;324:377-84.

10 Holdsworth MT, Fichtl RE, Behta M, et al. Incidence and impact of adverse drug events in paediatric inpatients. Arch Paediatr Adolesc Med 2003; 157:60-5

11 Kaushal R, Bates DW, Landrigan C, et al. Medication errors and adverse drug events in paediatric inpatients. JAMA 2001;285:21 14-20.

12 Whyte J, Greenan E. Drug usage and adverse drug reactions in paediatric patients. Acta Paediatr Scand 1977;66:767-75.

13 Ross LM, Wallace J, Paton JY. Medication errors in a paediatric teaching hospital in the UK: five years operational experience. Arch Dis Child 2000;83:492-7

14 Stephenson TJ. Commentary on LM Ross, $\mathrm{J}$ Wallace, JY Paton. Medication errors in a paediatric teaching hospital in the UK: five years operational experience. Arch Dis Child 2000;83:496-7

15 Koren G, Barzilay Z, Greenwald M. Tenfold errors in administration of drug doses: a neglected iatrogenic disease in paediatrics. Pediatrics 1986;77:848-9.

16 Kozer E, Scolnik D, Keays T, et al. Large errors in the dosing of medications for children. N Engl J Med 2002;346:1 175-6.

17 Kozer E, Scolnik D, Macpherson A, et al. Variables associated with medication errors in pediatric emergency medicine. Pediatrics 2002;110:823-6.

18 Bates DW, Leape LL, Cullen DJ, et al. Effect of computerized physician order entry and a team intervention on prevention of serious medication errors. JAMA 1998;280:1311-16.

19 Davis P. Health care as a risk factor. Can Med Assoc J 2004; 170: 1688-9. 
Research

\section{Good research conduct}

\section{J Grigg}

\section{A review of clinical research conduct}

G ood intentions alone are not enough to protect researchers from performing bad clinical research. This review examines areas that are most likely to cause problems, in particular duplicate publication, conflict of interest, authorship, and data storage. It also discusses the way journal editors approach research conduct issues, and how to create a research environment conducive to good research conduct.

The conduct of clinical research is increasingly governed by rules. Some are statutory, and others derive from guidelines drawn up by universities, funding bodies, and editors of medical journals. In the past, the conduct of research was a matter of passive trust between authors and journals, and between "hands on" researchers and their supervisors. In contrast, researchers and research managers must now actively work at maintaining good conduct in research. The UK Medical Research Council has identified the key research virtues as selflessness, integrity, objectivity, accountability, honesty, and leadership: ${ }^{1}$ qualities that, one hopes, all paediatricians would aspire to. But what relevance has this to dayto-day clinical research, beyond an aspiration to be good? Specifically, where do researchers unwittingly fall foul of acceptable standards of research conduct? This review is aimed at the well intentioned clinical researcher who strives to keep within the rules, and focuses on areas that cause the most problems.

\section{DUPLICATE PUBLICATION}

A duplicate publication is one that overlaps substantially with an article published elsewhere, and is usually published by the same author. ${ }^{2}$ Recently, authors of systematic reviews in anaesthesia found 103 potential duplicate publications (secondary publications) linked to 78 corresponding primary articles (that is, those published first). Specific patterns of duplication were identified. ${ }^{3}$ First was the straight copy, for example, where the results of a study were re-published in a pharmaceutical sponsored supplement. Second was where the data from a single multicentre trial were disaggregated into smaller subunits. The third pattern represented "data extension", where a preliminary article was extended by the addition of more data. The final pattern was chaotic - that is, where an article must have come from the same study, but both the study subjects and outcomes appeared different. Some of these practices are acceptable, but only if accompanied by transparency on the part of the authors. Indeed copies of papers may be published in a foreign language, if the English language journal allows. From the viewpoint of journal editors, problems arise when the intentions of authors are opaque. For example, the duplication study found that 65 secondary publications (including 11 of the translation copies) made no reference to the primary publication. There is no doubt that hidden (covert) duplication is bad publication practice. In some circumstances, this practice may even be construed as research misconduct, since these data may distort meta-analyses (different authors and different author order is no protection against duplication ${ }^{3}$ ), and may artificially enhance the data validity.

Unwitting duplicate publication may occur when different sets of observations have been obtained from the same group of patients. ${ }^{2}$ To prevent this, editors must be informed of any links between studies in the covering letters, copies of manuscripts (submitted, in press, or published) should be enclosed on submission, and any linked papers should be included in the references. Publishing linked data separately is a high risk enterprise: not only is there an increased chance of inadvertent covert duplication, but also of "salami" publication-where data are sliced into "smallest publishable units". Separate publication may be justified, if the researcher considers that the distinct issues have been addressed. However, it is important to ask oneself whether a single publication would present a more unified picture. An opinion from a colleague can provide a useful external viewpoint when this issue arises. Overlap of tables and the style and content of paragraphs may easily occur when writing multiple reviews on the same subject, ${ }^{4}$ and discussing previous reviews with the commissioning editor is essential. However, overlap of data per se does not preclude publication. There are consequences of getting this process wrong-with notices of duplicate publication, "naming and shaming" editorials, ${ }^{6}$ and replies which appear as excuses (box 1). Thus, to avoid duplicate or overlapping publications, authors should err on the side of caution when disclosing possible overlaps, take care in cross-referencing any overlapping publication (even at proof stage), and be aware of this as an issue.

\section{CONFLICT OF INTEREST}

Striving for scientific objectivity in conducting and writing up of clinical research help to protect readers of papers from developing a misleading impression of the significance of the data. Data stands on its own, but absolute objectivity when interpreting one's own study is probably never achieved. Well designed studies, especially those whose results are important irrespective of outcome, help researchers to be self-critical about data, and thus more able to recognise and discuss study limitations. At the other end of the spectrum, are researchers who are certain that their own data interpretation is objective $^{7}$ - a state that can lead to the evangelical promotion of false ideas. More subtle loss of objectivity may occur when writing up studies (for example, the failure to highlight study limitations, and quoting only data that support the study outcome), and it is worth remembering that: "nothing is so difficult as not deceiving oneself" (Ludwig Wittgenstein).

Some influences on objectivity, such as desire for knowledge, commitment to understanding disease in children,

Box 1: Responses given to an editor on discovery of duplicate publication $^{2}$

- "We did not read the instructions"

- "We wanted to reach a different audience"

- "We perceive the overlap to be much less than the reviewer or editor thinks"

- "Yes, we now see that we broke the rules, but this was not our intent" 
ambition, and academic reputation, are impossible to measure, but some negative influences are measurable and significant. For example, there is unequivocal evidence that financial ties have an effect on the research process. Stelfox and colleagues ${ }^{8}$ found a strong association between authors' published positions on the safety of calcium channel antagonists and their financial relationships with pharmaceutical manufacturers. More recently, Wittingdon and colleagues ${ }^{9}$ reported that, whereas published studies suggested a favourable risk-benefit profile for selective serotonin reuptake inhibitors, when combined with unpublished data, risks could outweigh benefits for the treatment of depression in children. ${ }^{9}$ An interpretation of these data is that financial or contractual considerations, inhibited clinicians from demanding publication. But clinical researchers have a duty to publish both positive and negative trial data, and should be aware that: (1) research funded by drug companies is less likely to be published than research funded by other sources; ${ }^{10}$ and (2) drug industry sponsored studies are more likely to have outcomes favouring the sponsor than differently funded studies, despite meeting acceptable quality criteria. ${ }^{10}$ Journal editors also have an important role in protecting against this bias towards publication of positive trials. To protect against bias, pharmaceutical companies must allow clinicians to examine the raw data, and not to require consent before submission of a manuscript for publication ${ }^{11}$ safeguards that should be in place before embarking on a contractual relationship. In the final manuscript, this relationship must be declared as a conflict of interest. ${ }^{11}$ What can be confusing is that a "financial conflict of interest" exists for the researcher not only when judgement has been overtly affected, but it also when judgement might or might be perceived to be affected..$^{12}$ Thus what researchers "feel" about their own objectivity is irrelevant when disclosing financial links-no matter how unimportant they appear to be to themselves.

A useful rule for conflict of interest issues is to declare all financial ties to companies that are broadly related to your area of research: (1) that would be regarded as personal income by the tax authorities; (2) are subsidised trips; (3) are research grants or "awards" from industry or sources with an interest in the study that are made to your research account; (4) involve pharmaceutical industry shares; and (5) are related to any other financially relevant factssuch as whether you hold a patent in the area. Not surprisingly, researchers

Box 2: Responses given to an editor on discovery of conflict of interest ${ }^{16}$

- "I didn't think that the policy applied to the type of (financial) relationship that I had"

- "The amount I received wasn't significant enough to merit declaring it"

- "This is an invasion of my privacy"

- "Your accusation is unjustified - show me the evidence that I was biased"

give stereotypical explanations when an undeclared conflict of interest is discovered (box 2). A recent case related to the paper published by Wakefield and colleagues, ${ }^{13}$ in which a payment from the Legal Aid Board for research in the same area was not declared at the time of submission. An editorial in The Lancet, subsequently stated that "we regret that aspects of funding for parallel and related work ... and the existence of ongoing litigation were not disclosed to the editors. We judge that all this information would have been material to our decision-making about the paper's suitability, credibility, and validity for publication". ${ }^{14}$ In this case the issue was not that the data were necessarily flawed, but that important information needed to place the authors interpretation (especially the speculation on the role of immunisation) in the appropriate context was missing: an interpretation that was subsequently retracted by most of the original authors. ${ }^{15}$

\section{AUTHORSHIP}

Collaborative activity is vital for clinical research. Yet the recent trend to quantify research in terms of the number of high impact papers published per unit time, means not only that authorship may bring prestige, but that rewards are directed to institutions. ${ }^{16}$ Given these pressures, it is not surprising that rules have been developed governing who can and cannot be included as an author. In 1985, the International Committee of Medical Journal Editors recommended that researchers should not be authors on work that they cannot defend publicly. ${ }^{17}$ More specifically, authorship should include the conception and design (or analysis) and interpretation of data, and drafting the article (or revising it critically for important intellectual content), and final approval of the version to be published. ${ }^{18}$ Thus authorship is not earned by the clinician who just gives permission for patients to be entered into a study, or by the head of department included for political reasons.

The number of authorship disputes has increased significantly over the past decade, at least in the USA. ${ }^{19}$ In order to prevent misunderstandings, the principal researcher should know who is to be the first and last author in the final publication before starting the study. The inclusion and order of other individuals can be delayed until the broad outline of the manuscript is established. In general, the first author is usually the hands-on clinician (for example, the research fellow), and the last author is the senior supervisor (who has written the grant application). The hands-on researcher should resist the temptation to offer "gift authorship" in order to curry favour. A recent trend that reduces some of the pressures on the first author from "fellow travellers" - is a published contributor statement detailing each individual's role. ${ }^{20}$ This doesn't stop individuals making false statements, but publication of contributor statements increases the chances of being found out.

Journal editors are often the first to hear about problems with authorship, duplicate publication, and conflicts of interest. In 1997, a self-help group of medical editors was formed (Committee on Publication Ethics, COPE), which by 2003 had expanded its membership to include editors from over 160 journals. ${ }^{21}$ At COPE meetings, editors present anonymised vignettes of problems, and the Committee advises on a plan of action. Authors are given an opportunity to reply to questions. COPE then provides advice on any further action to the relevant editor (for example, retraction, notice of duplicate publication, referral to the relevant university, hospital, or licensing body).

\section{DATA MANAGEMENT}

From May 2004, clinical trials in the UK must comply with the EU principals of "Good Clinical Practice" (GCP). This means that pharmaceutical industry standards of quality assurance, standard operating procedures, audits, and quality control systems are applied to all trials that assess "medicinal" products. ${ }^{22}$ The regulations cover trial design, ethics committee approval, establishment of adequate resources, review of documents by ethics committees, protocol compliance, consent, progress reports, safety reporting, and audit. A significant 
effect of this legislation is on trials funded by charities or by local institutions, where in the past, the principle investigator took the decision on how to record, handle, and store data. Now, even pilot studies involving medicines must be recorded so that there is an "audit trail" from the summary data, to data from individual study participants. The GCP legislation will also make it increasingly difficult to justify less rigorous methods of data handling in observational studies involving children. An additional requirement demanded by research councils, universities, and some journals, is that research data should be retained for at least five years (whether current clinical researchers could reconstruct their five year old publications using original data, is debatable). It is therefore the responsibility of all authors of a publication, to ensure that data are stored and formatted in such a way that an independent individual could easily reconstruct the published summary data and statistical analysis. Ideally, both paper and electronic files should be stored, and the electronic files should be re-saved annually onto the most recent storage device, using the latest version of the spreadsheet.

Why spend the time and effort archiving data? First, authors of systematic reviews often ask, several years after publication, for the original data in order to perform a meta-analysis. Second, archiving enables a full reanalysis to be performed if questions arise about the study's statistical analysis, or interpretation. For example, in 1993, Dockery and colleagues ${ }^{23}$ published a study on the effects of fossil fuel particles on health. The results were criticised by industry lobbyists, and since the findings had major implications for air quality guidelines, a reanalysis was commissioned in 2000 by the Health Effects Institute (Boston, USA). Its results confirmed the findings of the original study, and in doing this, strengthened its validity. ${ }^{24}$ In summary, data from studies involving children should be collected to the EU standard, irrespective of whether this is a legal requirement. Responsibility for ensuring that the data are archived lies with all of the authors, and continues for at least five years after publication.

\section{RESEARCH FRAUD}

In 2002, Jan Henrick Schön was found to have faked at least 17 published papers after astute readers noticed that a figure on molecular layer switching in Nature also appeared in a publication in Science related to a different device. ${ }^{25}$ At his peak, Schön was publishing on average a paper every eight days, but after the fraud's discovery, all of his publications were deemed to be untrustworthy. ${ }^{25}$ The definition of research fraud is confined to premeditated dishonesty: that is, fabrication (invention of data), falsification (wilful distortion of data), and plagiarism (copying large chunks of data and words without attribution). ${ }^{26}$ Thus there is a clear distinction between fraud and "suboptimal" research behaviour (see above).$^{25}$ Financial gain is not always the motivation behind fraud, since there are less overt rewards such as career advancement, ability to attract more research money, and an improved profile in research assessment exercises. Schön's hubris was his undoing, but fraud occurs in more subtle forms, for example, "pushing" data by cutting out inconvenient data points, or adding factitious points in a direction which the researcher guesses is probably correct. ${ }^{27}$ Although not proven, there is a strong suspicion that researchers who commit major frauds have probably been getting away with lesser frauds for years. ${ }^{28}$ Clinical researchers should not therefore feel threatened if collaborators request individual data. On the contrary, a lead author should expect co-authors to check original data underlying summary graphs and tables that are to be published in their name. Schön deleted his original data files, making it impossible to check his scientific claims, but one of his co-authors acknowledged that he "should have done more to confirm the accuracy of the papers". ${ }^{27}$ What should one do if you suspect a collaborator of research fraud? Whistle blowing is always difficult, ${ }^{29}$ and takes civil courage, but it remains the last checkpoint of good research conduct. Organisations such as UK universities and NHS trusts have pathways to express concerns, with major disciplinary consequences if the whistleblower is victimised. However, before embarking an official complaint, it is probably best to discuss things with a trusted independent senior colleague. ${ }^{30}$

\section{THE RESEARCH ENVIRONMENT}

Researchers do not act in isolation, and the ethos of good research practice must be ingrained into all research structures-from the top down. ${ }^{28}$ To date, there is little hard data on how institutional characteristics influence research integrity, ${ }^{28}$ and it may well be that that personal interactions are the most important determinant. Indeed, psychologists have recognised that socialisation with peers, review of research projects and outputs by peers, and an active and explicit adversarial system of criticism within local research structures, and at meetings, are essential "debiasing" techniques. ${ }^{7}$ Mentorship, traditionally done by senior academic paediatricians, plays a key role in ironing out sloppy practice, and can provide a life long role model of good conduct for young researchers: as long as the supervision is of high quality. Important components of mentorship are: (1) being available for formal scheduled meetings and informal discussions; (2) acting as an advocate; (3) insisting on completion of projects and checking data; (4) assisting with networking; and (5) seeking extramural funding. ${ }^{31}$ Whether the recent trend to merge some departments of paediatrics into more amorphous "scientific" entities (in order to improve research assessment exercise scores) will reproduce the critical mass of peers that will nurture and inspire the best quality of paediatric research practice, remains to be seen.

In the UK, partnerships between the NHS and universities have a key role in ensuing good research conduct in established researchers and teaching doctors in training. The size and power of these partnerships mean that they can be both responsive to local needs and innovative. For example, in August 2004, the Leicestershire and Northamptonshire and Rutland Denary funded two pilot posts in academic medicine for the second year of the Foundation Programme (F2) for newly qualified doctors. Doctors in these posts spend half of their out of call time in an academic medicine programme, which includes supervised training literature review and critical appraisal, good research practice, research study design, data interpretation, and presentation (Professor B Williams, Dr A Stanley, personal communication). Another option would be to second SpRs on a rotating basis to the "hands on" running of independent clinical trials with an "added on" structured training. Engagement of institutions with senior researchers should be an active process: a list of rules and aspirations published on the local intranet is not enough. When evaluating how seriously employers regard this issue, researchers should ask whether there is a central computer archive to lodge data, whether there is a critical mass of paediatric clinical researchers to provide mutual support and constructive criticism, and whether the institution has compulsory training in research conduct.

A variety of UK bodies provide guidance on good research practice (table 1). However, there is no central agency dedicated to review cases of misconduct-and to ensure that research employers actively promote this concept. To date, the UK General 
Table 1 Websites with information on research best practice, accessed December 2004

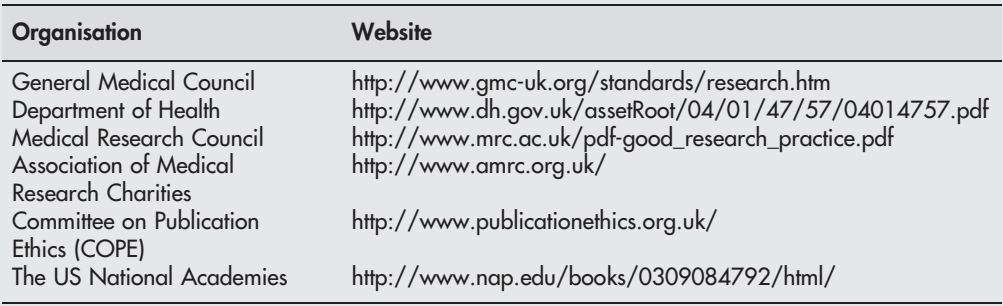

Medical Council, with its multiple roles, reacts to only the most serious cases of research misconduct. In a recent case, a researcher was suspended when he failed to: maintain complete and accurate records and retain them for audit, record research results accurately, keep the records secure, and consult with all the other authors when submitting the work for publication (http://www. gmc-uk. org/probdocs/decisions/pcc/2004/ SHAUKAT 20040219.htm, accessed December 2004). In contrast, Nordic countries have national committees dedicated to handling scientific dishonesty which have proved to be highly efficient and well regardedsomething that the UK could use as a model in the future. ${ }^{32}$

\section{SUMMARY}

To the paediatrician setting out on a research career it may seem that bureaucracy and rules exist to get in the way of, rather than to enable, clinical research. However, the presence of these rules and their complexity exist because clinical researchers have a unique responsibility to both science and patients. In commenting on scientific misconduct, Richard Horton (Editor, The Lancet) wrote "the chain of trust that links the patient to doctor, and doctor to researcher, is fragile. Research evidence strengthens this chain whereas fraud weakens it": $^{\prime 2}$ a statement which emphasises that research, when done well, should be a positive experience for all participants. Paediatric clinical research is certainly difficult to perform, and may indeed be currently undervalued. But its potential to impact directly on the care of children, in itself, provides sufficient reward if performed to the highest possible standard.

Arch Dis Child 2005;90:229-232.

doi: 10.1136/adc.2003.032672

Correspondence to: Dr J Grigg, Senior Lecturer in Paediatric Respiratory Medicine, Division of Child Health, Department of Infection, Immunity and Inflammation, University of Leicester, Leicester LE2 7LX, UK; ig33@le.ac.uk

\section{Accepted 5 August 2004}

Competing interests: The author has received financial support to attend conferences from Astra, 3M, Merck (UK), Glaxo-Wellcome, and Allen and Hanburys (UK). He has received payment for lectures given at educational meetings from Astra, Merck (UK), and GlaxoWellcome. He has been a co-investigator on a asthma genetics study funded by GlaxoWellcome, and has received an unrestricted research grant from Merck (UK).

\section{REFERENCES}

1 Medical Research Council. Good research practice. MRC external communications, 2000.

2 Tobin MJ. AJRCCM's policy on duplicate publication: infrequently asked questions Am J Respir Crit Care Med 2002;166:433-4.

3 von Elm E, Poglia G, Walder B, et al. Different patterns of duplicate publication: an analysis of articles used in systematic reviews. JAMA 2004;291:974-80.

4 Notice of duplicate publication. Thorax 2002;57:6.

5 Pavord ID, Morgan MD, Wardlaw AJ. Duplicate publication. Thorax 2002;57:1087.

6 Tobin MJ. Notice of duplicate publication. Am J Respir Crit Care Med 2002;166:625.

7 MacCoun RJ. Biases in the interpretation and use of research results. Annu Rev Psychol 1998;49:259-87.
8 Stelfox HT, Chua G, O'Rourke K, et al. Conflict of interest in the debate over calcium-channel antagonists. N Engl J Med 1998;338:101-6.

9 Whittington $\mathrm{CJ}$, Kendall T, Fonagy $\mathrm{P}$, et al. Selective serotonin reuptake inhibitors in childhood depression: systematic review of published versus unpublished data. Lancet 2004;363:1341-5.

10 Lexchin J, Bero LA, Diulbegovic B, et al. Pharmaceutical industry sponsorship and research outcome and quality: systematic review. BMJ 2003;326:1167-70.

11 Davidoff F, DeAngelis CD, Drazen JM, et al. Sponsorship, authorship, and accountability. Lancet 2001;358:854-6.

12 Tobin MJ. Conflicts of interest and AJRCCM: restating policy and a new form to upload. Am J Respir Crit Care Med 2003;167:1161-4.

13 Wakefield AJ, Murch SH, Anthony A, et al. lleallymphoid-nodular hyperplasia, non-specific colitis, and pervasive developmental disorder in children. Lancet 1998;351:637-41.

14 Horton R. A statement by the editors of The Lancet. Lancet 2004;363:820-1.

15 Murch SH, Anthony A, Casson DH, et al. Retraction of an interpretation. Lancet 2004;363:750.

16 Lawrence PA. The politics of publication. Nature 2003:422:259-61.

17 Guidelines on authorship. International Committee of Medical Journal Editors. BMJ (Clin Res Ed) 1985;291:722.

18 Bhopal R, Rankin J, McColl E, et al. The vexed question of authorship: views of researchers in a British medical faculty. BMJ 1997;314:1009-12.

19 Wilcox L. Authorship: the coin of the realm, the source of complaints. JAMA 1998;280:216-17.

20 Yank V, Rennie D. Disclosure of researcher contributions: a study of original research articles in The Lancet. Ann Intern Med 1999;130:661-70.

21 Committee on Publication Ethics. The COPE report 2003. London: BMJ Books, 2004.

22 Jorgensen A, Bach KF, Friis K. Good Clinical Practice is now obligatory in academic clinical drug research in the European Union. Pharmacol Toxicol 2004;94:57-8

23 Dockery DW, Pope AC3, Xu X, et al. An association between air pollution and mortality in six U.S. cities. N Engl J Med 1993;329:1753-9.

24 Krewski D, Burnett RT, Goldberg MS, et al. Reanalysis of the Harvard six cities study and the American Cancer Society study of particulate air pollution. Cambridge, MA: Health Effects Institute, 2000: 1-295.

25 Service RF. Scientific misconduct. Bell Labs fires star physicist found guilty of forging data. Science 2002;298:30-1.

26 Waldman M. Health department lays down law on scientific misconduct. Nature 2004;428:786

27 Fenning TM. Fraud offers big rewards for relatively little risk. Nature 2004;427:393.

28 Anon. Integrity from the top down. Nature 2002;418:569.

29 Rhodes R, Strain JJ. Whistleblowing in academic medicine. J Med Ethics 2004:30:35-9.

30 McGuire R. Blowing the whistle-safely. BM 2004;328:s7.

31 Bauchner H. Mentoring clinical researchers. Arch Dis Child 2002;87:82-4.

32 Horton R. Scientific misconduct: exaggerated fear but still real and requiring a proportionate response. Lancet 1999;354:7-8. 
Ethics

\section{Informing children and parents about research}

\section{A Dawson, S A Spencer}

\section{A discussion of the difficulties involved}

C urrent international, ${ }^{12}$ European, ${ }^{34}$ and $U^{5}{ }^{6}$ research frameworks require all competent participants in research to give an informed consent. An informed consent can be defined as a decision made by a competent individual, free of any undue influence, on the basis of all of the relevant information. ${ }^{7}$ Evidence exists that difficulties in obtaining an informed consent are leading to recruitment failure in essential paediatric research. ${ }^{8}$ Clinical research is vital to ensure that patients receive the best possible treatments. Such research either improves the quality of care or saves lives. For example, clear benefits can be shown from the results of childhood cancer trials. ${ }^{9}$ Research is especially important in relation to children, given the poor evidence base for much of paediatrics. ${ }^{35}$ It is therefore necessary to use all possible means to improve the ability of parents and children to come to an informed position regarding research proposals, so that recruitment into such research is maintained. This review outlines a series of potential impediments to realising this objective in relation to paediatric research, provides a number of recommendations for improvements in practice, as well as suggesting some future avenues for research.

\section{CHILDREN, PARENTS, AND COMPETENCE}

Obtaining informed consent is particularly challenging for research involving children and parents because of the issue of competence. Where a child can be deemed competent to understand the nature and implications of research, he/ she must be fully involved in the consent process. ${ }^{5}$ There is a great deal of empirical evidence to suggest that many children are capable of much greater participation than was thought possible in the past. ${ }^{10}{ }^{11}$ This has resulted in the present consensus position that where a competent child is able to give an informed consent, this is acceptable, although normally parents will also be asked when the child is under $18 .^{5}$ This is often phrased in terms of gaining "assent" from the child, even though such a phrase has no legal meaning. ${ }^{12}$ As a consequence both children and parents may be involved in the consent process. This can lead to conflict, and differences have been recorded in relation to the assessment of risk and whether participation is appropriate. ${ }^{13}$ In cases of disagreement between parent and child, a parent cannot overrule a competent child's decision, but a clinician is unlikely to go ahead with research if either the child or the parent is reluctant.

Where neonates, young children, or older children who are not yet competent are concerned, informed consent is sought from a person with parental responsibility. ${ }^{12}$ It must be noted that fathers do not automatically have parental responsibility unless the parents were married at the time the child was born. Issues relating to competence may also arise when the circumstances surrounding the research are not conducive to the retaining of information. For example, much of paediatrics is acute, so the child is likely to be ill and the parents may be feeling confused or overwhelmed. Parents of a child newly diagnosed with cancer, for example, may be shocked by the diagnosis and yet have to quickly come to a decision about whether to include their child in a randomised trial. Consent for research on preterm neonates is also likely to present difficulties, given the fact that the mother may be tired or unwell following a difficult or unexpected delivery, and stressed about the condition of a child receiving intensive care. Yet many important neonatal trials have required consent to be obtained quickly in the first days of life. ${ }^{14}$

\section{PROBLEMS IN INFORMATION PROVISION}

Such problems in relation to competence are compounded by those arising in relation to information provision. The existing research frameworks offer guidance about what constitutes information necessary for an informed consent. ${ }^{12}$ Essential information includes not only that about the nature and purpose of the specific research, but also the relevant balance between possible risks and benefits, as well as information about the implications of participation (including that the study is voluntary, and that failure to consent will not jeopardise clinical care). Information about relevant methodological issues should also be included as appropriate; for example, participation in a randomised controlled trial should be preceded by explanation of such concepts as randomisation, blinding, and equipoise. Patients must also be informed about the source of project funding and any potential conflicts of interests. $^{5}$

Such requirements look difficult, if not impossible, to attain, given the evidence suggesting that many patients find it difficult to understand and recall elements of the research process even a short time after agreeing to participate. ${ }^{15}$ Some such problems may relate to difficulty understanding the language used in the design of studies, and this could, perhaps, be overcome by rewording the information provided. However, this cannot be the whole story. While it is, perhaps, not surprising that parents may struggle to understand elements of research methodology such as the role of randomisation and its benefits, ${ }^{14}$ patients' recall of even simple events such as receiving a leaflet is remarkably low. ${ }^{16}$ In fact parental comprehension of all aspects of research is consistently judged to be poor. ${ }^{17}$ As suggested above, such problems are only likely to be magnified in an acute setting where the competent child or parents may be upset, confused, and ill.

\section{IMPROVING INFORMATION PROVISION}

Despite these findings, it might be argued that successful informed consent procedures can be put in place if only good quality and accessible information is available for both competent children and parents. There is a large literature exploring ways of improving communication through the provision and refinement of information. ${ }^{18}$ However, there are remarkably few studies looking at the informational needs of children, whether these needs are met, and if not, how they may be addressed.

The provision of an information sheet or leaflet, is now a requirement, as part of the ethical review process, and has to follow a standardised format. ${ }^{19}$ Is there any evidence that information sheets promote informed choice? While one study suggests that they make little, if any, difference,,$^{20}$ other studies are more positive and suggest improved satisfaction with the information received and some evidence of anxiety reduction. ${ }^{21}{ }^{22}$ 
These studies recommend that such leaflets should be used to augment the verbal explanation given as part of recruitment, and not as a substitute for it. In producing written material it is considered to be important to seek to involve consumer and patient groups. ${ }^{23}$ Information leaflets can then be refined in the light of patients' views and comprehension. For example, the acceptability of a potentially controversial trial can also be explored with patients at a theoretical level. ${ }^{23}$

Little attention has been paid to how children might be included in the development of leaflets designed to inform future competent child participants. Should children be engaged in the production of material to meet these specific requirements? If it is thought that they should be, how, and when, is it best to do so? There are currently no answers to these questions in the published literature. In fact, most existing research on communication issues in relation to consent for child participants in research has been carried out with consenting parents and not with competent children. Researchers have explored parental comprehension of factors relevant to giving an informed consent, ${ }^{24}$ including the factors that influence parental decision making in relation to enrolment of their child into a research study. ${ }^{25}$ Researchers need to explore these same issues, urgently, with competent children.

There is strong evidence that the usefulness and clarity of written material can be improved, ${ }^{26-28}$ and publications are available to help with this task. ${ }^{29}{ }^{30}$ However, it is not clear that this material is of any assistance in improving communication with children. For example, while the Consumers for Ethics in Research (CERES) leaflet suggests that children should be required to give a consent if they are competent, there is no discussion as to whether this will be equally or more difficult than gaining an informed consent from an adult. ${ }^{31}$ In the general literature concerning the production of written materials for gaining consent, ${ }^{29}{ }^{30}$ there is virtually no exploration of the role of written materials in the comprehension of research and subsequent informed consent in competent children. ${ }^{32}$ On the other hand, there are many good examples of written materials, such as leaflets and websites, that have been prepared for children to help them understand chronic condition such as asthma, diabetes, and cancer. ${ }^{33-35}$ Although there is little current evidence of the evaluation of such materials, they might provide a model for leaflets and web resources for competent children in relation to clinical research.
There is, therefore, an urgent need for more empirical research on competent children's comprehension of information relating to research and their views about the acceptability of research. In fact, even the studies with adults might be open to some criticism, as they are generally small scale and involve rather subjective outcome measures (such as self reported "satisfaction" or "sense of being fully informed"). Further work is needed using larger sample sizes, more robust methodologies, and the inclusion of competent children.

Another obvious issue is whether children are more likely to understand and retain information presented in a video or multimedia format. Unfortunately little work has been done with children, and the results from studies with adults are inconclusive. On the one hand, some studies suggest that the provision of information in the form of a video results in increased knowledge and retention of information in comparison with leaflets, ${ }^{36}{ }^{37}$ whereas other studies have found no additional benefits beyond written information. ${ }^{38} 39$ The evidence in relation to the use of videos on willingness to participate in research is also equivocal. ${ }^{36}{ }^{37}$ There has been very little research on patients' reception of information via multimedia formats. One published study compared outcomes in relation to information provided to children via written information sheets or multimedia software in relation to enuresis. It found no significant difference between the two groups. However, the study is of limited value, as it did not explicitly explore whether there was any difference in comprehension between the two groups as a result of the intervention. ${ }^{32}$ Once again there is a need for further research in this area.

\section{HOW MIGHT THE CONSENT PROCESS BE IMPROVED?}

Many of the difficulties in obtaining an informed consent for research with children, relate to the problem of imparting information in a stressful or even emergency situation. The low levels of knowledge and understanding of research methodology in the general population compound this difficulty. This raises the question whether there are any ways to better inform this patient population and, if so, whether this would assist those who were subsequently asked to participate in research to give an informed consent.

Much of the general literature published on information provision procedures relates to attempts to test or obtain consent at the point of participation in a specific research project. ${ }^{18}$ However, one investigation into the impact of an information leaflet on understanding of medical research outside of a specific research context provided some evidence of benefit. ${ }^{40}$ The leaflet was judged by the majority of participants to provide welcome information about research and to have had the desired effect in raising the profile of research. It also revealed a general willingness to participate in research. Whether prior exposure to such a leaflet actually helps with the obtaining of an informed consent to a specific project has not yet been tested.

Other possibilities for the education of parents and children about research in general could include the use of video presentations in waiting areas and in antenatal clinics/classes for expectant mothers. Perhaps there is also a role here for the media and for schools. If clinical research is important for the continued development of medicine and wellbeing of society, perhaps it should be given as high a priority as information about drugs, AIDS, sex education, and other lifestyle health issues.

\section{SOME PRACTICAL IMPLICATIONS OF THESE ISSUES RELATING TO INFORMED CONSENT}

Much of the research presented in this paper shows the existence of real problems in gaining informed consent, despite the requirement to do so. This fact presents two very practical dangers. The first is that despite signing a consent form, the participants may later complain that they did not at the time understand the implications of what they were signing. ${ }^{41}$ This concern provides a practical motivation to consider ways to improve information provision to add to the ethical justification already discussed above.

The second practical concern is that given the existence of both the requirement to gain an informed consent, and the evidence about the problems in gaining an informed consent, researchers are likely to be increasingly cautious about recruiting into trials. In a situation where responsibility lies with the researcher to ensure that the participants are competent, have fully understood the relevant information, and have given an informed consent, ${ }^{6}$ many researchers will choose not to enrol patients in research because of concerns about attaining these ends, despite believing that participation in the research will be in the patients' best interests. Are we really protecting these patients by denying them the opportunity to take part in research? While it is clearly the case that children need to be protected from unethical research, it also needs to be accepted that one consequence of insisting on gaining 
informed consent will be that recruitment into trials involving children will become more difficult, ${ }^{8}$ and past successful research ${ }^{9}$ will become more difficult to emulate. The overall result will be that children will be harmed, as vital research will not be performed.

\section{CONCLUSION}

There is a strong imperative to ensure that informed consent is obtained from every competent research participant, whether adult or competent child. However, there are a number of barriers to obtaining informed consent. Therefore there is a clear need to develop better methods of imparting information at the time of recruitment into studies and a need to explore methods of increasing both the knowledge and understanding of medical research in all consumers of health care services, so they will be better prepared to make an informed choice should the opportunity to participate in research arise. It has been noted that the information needs of competent children who are also required to make informed choices about research has largely been neglected. This requires urgent remedy. Finally, it needs to be acknowledged that the imperative to seek an informed consent may result in much less research in vulnerable groups. This is potentially harmful and it is not clear that this is a price worth paying.

Arch Dis Child 2005;90:233-235.

doi: 10.1136/adc.2003.038257

\section{Authors' affiliations}

A Dawson, Centre for Professional Ethics,

Keele University, UK

S A Spencer, Neonatal Unit, North

Staffordshire University Hospital NHS Trust,

Stoke on Trent, UK

Correspondence to: Dr S A Spencer, Neonatal Unit, North Staffordshire University Hospital NHS Trust, City General, Newcastle Road, Stoke on Trent ST4 6QC, UK; andy.spencer@ uhns.nhs.uk

Competing interests: none declared

\section{REFERENCES}

1 The Declaration of Helsinki. Amended 2000, with clarification 2002. http://www.wma.net/e/ policy/b3.htm.
2 Council for International Organizations of Medical Sciences. International ethical guidelines for biomedical research involving human subjects, 2002 (http://www.cioms.ch/ frame_guidelines_nov_2002.htm)

3 Gill D. Ethical principles and operational guidelines for good clinical practice in paediatric research. Recommendations of the Ethics Working Group of the Confederation of European Specialists in Paediatrics (CESP). Eur J Pediatr 2004; 163:53-7.

4 Directive 2001/20/EC of the European Parliament and of the Council of 4 April 2001 http://europa.eu.int/eur-lex/pri/en/oj/dat/ 2001//_121/I_12120010501en00340044.pdf.

5 Royal College of Paediatrics, Child Health: Ethics Advisory Committee. Guidelines for the ethical conduct of medical research involving children. Arch Dis Child 2000;82:177-82.

6 Department of Health. Governance arrangements for NHS research ethics committees. DoH, 2001.

7 Brock D. Informed consent. In: VanDeVeer D Regan T, eds. Health care ethics: an introduction. Philadelphia: Temple University Press, 1987.

8 Nicklin SE, Spencer SA. Recruitment failure in early neonatal research. Arch Dis Child Fetal Neonatal Ed 1994;89:F281.

9 Stiller CA, Bunch KJ. Trends in survival for childhood cancer in Britain diagnosed 1971-85. Br J Cancer 1990:62:806-15.

10 Alderson P. Children's consent to surgery. Buckingham: Open University Press, 1993.

11 Kuther TL. Medical decision-making and minors: issues of consent and assent. Adolescence 2003;38:343-58

12 British Medical Association. Consent, rights and choices in health care for children and young people. London: BMJ Books, 2001.

13 Brody JL, Scherer DG, Annett RD, et al. Voluntary assent in biomedical research with adolescents: a comparison of parents and adolescent views. Ethics and Behavior 2003;13:79-95.

14 Snowdon C, Garcia J, Elbourne D. Making sense of randomisation; responses of parents of critically ill babies to random allocation of treatment in a clinical trial. Soc Sci Med 1997:45:1337-55.

15 Kent G. Shared understandings for informed consent: the relevance of psychological research on the provision of information. Soc Sci Med 1996;43:1517-23.

16 Taylor EM, Parker S, Ramsay MP. Patients' receipt and understanding of written information about a resuscitation policy. Bioethics 1998;12:64-76.

17 Harth SC, Thong YH. Parental perceptions and attitudes about informed consent in clinical research involving children. Soc Sci Med 1995;41:1647-51.

18 Sugarman J, McCrory D, Powell D, et al. Empirical research on informed consent: an annotated bibliography. Hastings Center Report 1999;29(suppl):S1-42.

19 Central Office for Research Ethical Committees (COREC). Guidelines for researchers. Patient information sheet and consent form. http://www.corec.org.uk/wordDocs/pis.doc

20 O'Cathain A, Walters SJ, Nicholl JP, et al. Use of evidence based leaflets to promote informed choice in maternity care: randomised controlled trial in everyday practice. BMJ 2001;324:643-6.

21 Bellew M, Atkinson K, Dixon G, et al. The introduction of a paediatric anaesthesia information leaflet: an audit of its impact on parental anxiety and satisfaction. Paediatr Anaesthes 2002;12:124-30.

22 Garrud P, Wood M. Stainsby L. Impact of risk information in a patient education leaflet. Patient Educ Couns 2001;43:301-4.

23 Koops L, Lindley RI. Thrombolysis for acute ischaemic stroke: consumer involvement in design of new randomised controlled trial. BMJ 2002;325:415-19.

24 Kupst MJ, Patenaude AF, Walco GA, et al. Clinical trials in pediatric cancer: parental perspectives on informed consent. J Pediatr Hematol Oncol 2003;25:787-90.

25 Tait AR, Voepel-Lewis T, Malviya S. Participation of children in clinical research: factors that influence a parent's decision to consent. Anesthesiology 2003;99:819-25.

26 Clark CR. Creating information messages for reducing patient distress during health care procedures. Patient Educ Couns 1997;30:247-55.

27 Beaver K, Luker K. Readability of patient information booklets for women with breast cancer. Patient Educ Couns 1997;31:95-102.

28 Biorn E, Rossell P, Holm S. Can the written information to research subjects be improved? An empirical study. J Med Ethics 1999;25:263-7

29 Coulter A, Entwhistle V, Gilbert D. Informing patients: an assessment of the quality of patient information materials. London: Kings Fund Publishing, 1998

30 Duman M. Producing patient information: how to research, develop \& produce effective information resources. London: King's Fund, 2003.

31 Consumers for Ethics in Research (CERES). Health research and you: what you need to think about, 2003. www.ceres.org.uk.

32 Redsell SA, Collier J, Garrud P, et al. Multimedia versus written information for nocturnal enuresis education: a cluster randomised controlled trial. Child Care Health Dev 2003;29:121-9.

33 http://www.asthma.org.uk/kidszone/ index.php.

34 http://www.childrenfirst.nhs.uk/kids/health/ illnesses/diabetes.html.

35 http://www.icnet.uk/kids/cellsrus/cellsrus.html.

36 Weston J, Hannah M, Downes J. Evaluating the benefits of a patient information video during the informed consent process. Patient Educ Couns 1997;30:239-45.

37 Hewison J, Cuckle H, Baillie C, et al. Use of videotapes at home to inform choice in Down syndrome screening: a randomised controlled trial. Prenat Diagn 2001;21:146-9.

38 Hopper KD, Zajdel M, Hulse SF, et al. Interactive method of informing patients of the risks of intravenous contrast media. Radiology 1994; 192:67-71.

39 Jepson R, Forbes C, Sowden A, et al. Increasing informed uptake and non-uptake of screening: evidence from a systematic review. Health Expectations 2001;4:116-30.

40 Spencer SA, Dawson A, Rigby C, et al. Informing patients about research-evaluation of an information leaflet. Quality in Primary Care 2004; 12:37-46.

41 NHS Executive West Midlands Regional Office. Report of a review of the research framework in North Staffordshire Hospital NHS Trust (Griffiths report). Leeds, 2000 (www.doh.gov.uk/wmro/ northstaffs.htm). 